\title{
1 Exon probe sets and bioinformatics pipelines for all levels of fish phylogenomics
}

3 Lily C. Hughes ${ }^{1,2,3, *}$, Guillermo Ortî ${ }^{1,3}$, Hadeel Saad ${ }^{1},{\text { Chenhong } \mathrm{Li}^{4} \text {, William T. White }}^{5}$, Carole

4 C. Baldwin ${ }^{3}$, Keith A. Crandall ${ }^{1,2}$, Dahiana Arcila ${ }^{3,6,7}$, and Ricardo Betancur-R. ${ }^{7}$

$6{ }^{1}$ Department of Biological Sciences, George Washington University, Washington, D.C., U.S.A.

$7 \quad{ }^{2}$ Computational Biology Institute, Milken Institute of Public Health, George Washington

8 University, Washington, D.C., U.S.A.

$9{ }^{3}$ Department of Vertebrate Zoology, National Museum of Natural History, Smithsonian

10 Institution, Washington, D.C., U.S.A.

$11{ }^{4}$ College of Fisheries and Life Sciences, Shanghai Ocean University, Shanghai, China

$12{ }^{5}$ CSIRO Australian National Fish Collection, National Research Collections of Australia,

13 Hobart, TAS, Australia

$14{ }^{6}$ Sam Noble Oklahoma Museum of Natural History, Norman, O.K., U.S.A.

$15{ }^{7}$ Department of Biology, University of Oklahoma, Norman, O.K., U.S.A.

16

17 *Corresponding author: Lily C. Hughes, lilychughes@gmail.com.

18 Current address: Department of Organismal Biology and Anatomy, University of Chicago,

19 Chicago, IL.

21 Keywords: Actinopterygii, Protein coding, Systematics, Phylogenetics, Evolution, Target

22 capture 


\section{Abstract}

25 Exon markers have a long history of use in phylogenetics of ray-finned fishes, the most diverse

26 clade of vertebrates with more than 35,000 species. As the number of published genomes

27 increases, it has become easier to test exons and other genetic markers for signals of ancient

28 duplication events and filter out paralogs that can mislead phylogenetic analysis. We present

29 seven new probe sets for current target-capture phylogenomic protocols that capture 1,104 exons

30 explicitly filtered for paralogs using gene trees. These seven probe sets span the diversity of

31 teleost fishes, including four sets that target five hyper-diverse percomorph clades which

32 together comprise ca. 17,000 species (Carangaria, Ovalentaria, Eupercaria, and Syngnatharia +

33 Pelagiaria combined). We additionally included probes to capture exon markers that have been

34 commonly used in fish phylogenetics, despite some being flagged for paralogs, to facilitate

35 integration of old and new molecular phylogenetic matrices. We tested these probes and merged

36 new exon-capture sequence data into an existing data matrix of 1,105 exons and 300 ray-finned

37 fish species. We provide an optimized bioinformatics pipeline to assemble exon capture data

38 from raw reads to alignments for downstream analysis. We show that loci with known paralogs

39 are at risk of assembling duplicated sequences with target-capture, but we also assembled many

40 useful orthologous sequences. These probe sets are a valuable resource for advancing fish

41 phylogenomics because they can be easily extracted from increasingly available whole genome

42 and transcriptome datasets, and also may be integrated with existing PCR-based exon and

43 mitochondrial datasets.

\section{Introduction}


46 Exon markers have played a pivotal role in resolving phylogenetic relationships among ray-

47 finned fishes (Li et al. 2007; Near et al. 2012; Betancur-R. et al. 2013; Betancur-R et al. 2017;

48 Hughes et al. 2018; Rabosky et al. 2018). Identification of these exons has typically involved the

49 comparison of a small number of fish model genomes. For example, a suite of 154 single-copy

50 exons conserved enough for PCR amplification was identified by Li et al. (2007). This study

51 used a reciprocal BLAST approach on two genomes, the pufferfish Takifugu rubripes and the

52 zebrafish Danio rerio, with 10 exons initially optimized with PCR primers for sequencing (Li et

53 al. 2007). These exons demonstrated their utility for resolving previously enigmatic relationships

54 among fishes (Li et al. 2008), and were the basis for largescale reappraisals of the ray-finned fish

55 Tree of Life (Near et al. 2012; Betancur-R. et al. 2013), phylogenetic analysis of the large clade

56 of the "spiny-ray" acanthomorph fishes (Near et al. 2013b), and new phylogenetic classifications

57 based on sequence data for more than 2,000 fish species (Betancur-R. et al. 2013; Betancur-R et

58 al. 2017). Most recently, these exons formed a large part of a supermatrix analysis that utilized

59 sequence data for more than 11,000 ray-finned fish species available through GenBank in one of

60 the largest analyses to date (Rabosky et al. 2018).

62 The advent of high-throughput sequencing technologies has drastically increased the number of

63 loci systematists can harness for their groups of interest. Sequence capture based on single-

64 stranded RNA probes that enrich genomic DNA libraries for conserved molecular markers have

65 revolutionized phylogenomics (Faircloth et al. 2012; Lemmon et al. 2012), allowing cost-

66 effective sequencing of hundreds or thousands of markers for many taxa. Ultraconserved

67 Elements (UCEs) (Faircloth et al. 2012) have been used for fish phylogenomics (Faircloth et al.

68 2013, 2020; Harrington et al. 2016; Longo et al. 2017; Chakrabarty et al. 2017; Alfaro et al. 
2018; Roxo et al. 2019; Friedman et al. 2019), as have Anchored Hybrid Enrichment (AHE) approaches (Lemmon et al. 2012; Eytan et al. 2015; Stout et al. 2016; Dornburg et al. 2017;

71 Irisarri et al. 2018). But exon markers have desirable properties for phylogenomics that other

72 approaches may lack. They are relatively easy to align, and a number of software programs have

73 been developed for reading frame-aware alignment (Abascal et al. 2010; Ranwez et al. 2011,

74 2018), avoiding potential homology errors with UCE flanking regions that are more difficult to

75 align (Edwards et al. 2017). Both protein and nucleotide sequences can be used for phylogenetic

76 inference, making them useful for deep (Hughes et al. 2018) and shallow phylogenetic scales

77 (Rincon-Sandoval et al. 2019). Exon markers are also easy to integrate with both genomic and

78 transcriptomic data, with sequences being produced and archived for a variety of studies from

79 comparative genomics to gene expression analysis that can provide resources for systematists to

80 increase taxon sampling without incurring additional costs.

82 Since exon markers tend to be more variable across the target region than UCEs or AHE, two

83 rounds of in vitro hybridization are optimal for their sequence capture protocols (Li et al. 2013).

84 This improvement in laboratory techniques has resulted in a number of studies using sequence

85 capture to target exons for fish phylogenomics (Ilves \& López-Fernández 2014; Li et al. 2015;

86 Song et al. 2017; Arcila et al. 2017; Ilves et al. 2017; Kuang et al. 2018; Straube et al. 2018;

87 Betancur-R. et al. 2019; Rincon-Sandoval et al. 2019; Yin et al. 2019). The increase in genomic

88 resources for fishes has allowed for the comparison of a larger number of genomes for probe

89 design (Li et al. 2012), and ultimately eight ray-finned fish genomes were used to identify

$90>17,000$ 'single-copy' exons (Song et al. 2017) using a modification of the reciprocal BLAST

91 approach of Li et al. (2007). A subset (4,434) of these were optimized for capture across all ray- 
92 finned fishes (Jiang et al. 2019). Other sets of exon probes have been designed to target more

93 specific groups including cichlids (Ilves \& López-Fernández 2014), and otophysans (Arcila et al.

94 2017).

95

96 The evolutionary history of vertebrate genomes is complicated by two ancient Whole-Genome

97 Duplication (WGD) events, and an additional WGD event in the ancestor to all modern teleosts

98 (Vandepoele et al. 2004; Dehal \& Boore 2005). While many duplicated gene copies were lost

99 shortly after the teleost WGD (Inoue et al. 2015), up to a quarter of genes in teleost genomes

100 have paralogs as a consequence of this event (Braasch et al. 2015). Phylogenetic inference relies

101 on the analysis of orthologs, but loci implemented so far for analyses were based on the

102 comparison of a limited number of model genomes and some threshold of similarity to define

103 them as "single-copy" (Li et al. 2007). A recent study implementing an explicit tree-based

104 filtering method to test for orthology revealed that one third of the 'single-copy' exons >200 bp

105 in length identified by Jiang et al. (2019) were affected by paralogy, potentially biasing tree

106 inference (Hughes et al. 2018). A set of 1,105 exons free of vertebrate and teleost WGD-derived

107 paralogs identified in this study resolved the phylogeny with confidence for more than 300

108 species of ray-finned fishes. Other markers used for phylogenomic studies such as UCEs

109 (Faircloth et al. 2013), AHE loci (Lemmon et al. 2012) and exons (Ilves \& López-Fernández

110 2014; Song et al. 2017; Arcila et al. 2017; Jiang et al. 2019) also have not been explicitly tested

111 for paralogy using approaches based on gene trees.

112

113 Here we present a new experimental protocol to obtain sequence data for a set of exons filtered

114 for paralogs (Hughes et al. 2018) across the diversity of fishes. We provide probe sets for target- 
115 capture that are designed to enrich genomic libraries for different taxonomic groups, from the

116 early branching teleosts to the major groups within percomorphs, the massive radiation

117 comprising more than 17,000 species. These probe sets target the same loci, but the specific

118 sequences of the probes are tailored to capture more efficiently within taxonomic brackets. We

119 have also included probes for other legacy exon markers (e.g., Lopez et al. 2004; Lovejoy et al.

120 2004; Dettai \& Lecointre 2005; Li et al. 2007) and mitochondrial DNA (mtDNA) loci that have

121 been sequenced for a large number of fishes through PCR-Sanger sequencing methods to

122 facilitate integration of new high throughput sequencing results with existing phylogenetic

123 datasets. We designed a new bioinformatics pipeline that wraps aTRAM 2.0 (Allen et al. 2017)

124 with other software packages and python scripts to assemble and filter sequence alignments from

125 Illumina reads.

\section{Methods}

128 Nuclear Exon Probes

129 Sequences for probe design came from exon alignments derived from a database of 303 bony

130 fish genomes and transcriptomes (Sun et al. 2016; Hughes et al. 2018). Briefly, the EvolMarkers

131 pipeline (Li et al. 2012, 2015; Jiang et al. 2019) was used to identify 1,721 single-copy exons in

132 eight ray-finned fish genomes (Lepisosteus oculatus, Anguilla japonica, Danio rerio, Gadus

133 morhua, Oreochromis niloticus, Oryzias latipes, Tetraodon nigroviridis, and Gasterosteus

134 aculeatus). These exons were mined from 295 other genomes and transcriptomes using nhmmer

135 (Wheeler \& Eddy 2013) in HMMER v3.1b2, and exons with paralogs were filtered by testing for

136 duplications in gene trees via topology tests (see Hughes et al. 2018 for full details). 
138 A total of 1,105 exons were retained after filtering for loci with paralogs. We generated seven

139 probe sets for these exons based on different underlying references for our target groups,

140 following the classification of Betancur-R. et al. (2017). These seven target teleost groups

141 included (i) Elopomorpha ( 1000 species, including true eels and tarpons) (Figure 1); (ii) early

142 branching teleosts from Osteoglossomorpha (bonytongues) to Myctophiformes (lanternfishes) —

143 hereafter paraphyletic "Backbone 1" (Figure 1); (iii) Acanthomorphata (from

144 paracanthopterygians (e.g. cods, oarfish) to Anabantaria (e.g. swamp eels, gouramies)—

145 hereafter paraphyletic "Backbone 2") (Figure 2); and four specific sets aimed for some of the

146 most species-rich clades of Percomorphaceae, including (iv) Carangaria ( 1,100 species,

147 including flatfishes and jacks) (Figure 3); (v) Ovalentaria ( 5,600 species, including clownfishes,

148 cichlids, flying fishes) (Figure 2); (vi) Eupercaria ( 6,800 species, including surgeonfishes,

149 pufferfishes, and groupers) (Figure 3); and (vii) Syngnatharia-Pelagiaria ( 1,000 species,

150 including tunas, seahorses, and pipefishes) (Figure 3). The large freshwater Otophysa clade

151 (>10,000 species, including catfishes, knifefishes, and tetras) is not included in Backbone 1

152 (Figure 1), largely because it was targeted earlier by a more specific probe set designed for the

153 clade by other exon-capture fish studies (Arcila et al. 2017; Betancur-R. et al. 2019), though 143

154 exons are shared between the two. We designed probe sets for different subsets of taxa from

155 these 1,105 alignments that initially consisted of 303 species that span the diversity of bony

156 fishes (Hughes et al. 2018), as explained above. Each of the seven probe set references were

157 comprised four to eight of the most phylogenetically-distant taxa in the target clade, depending

158 on the phylogenetic breadth the probe set covers (Table 1). We ranked preferred taxa within each

159 of these groups to form the basis for the probe set references (Table 1), and if all preferred taxa

160 were missing from a group, we took the next longest sequence in the alignment for the clade of 
161 interest. This means that some exons may have unique taxa representing them in their reference

162 set. One particularly long exon included highly divergent sequences that were difficult to align

163 and was ultimately excluded from the final probe sets (a total of 1,104 target exons remained).

165 We included baits for nuclear markers popular in fish phylogenetics (hereafter referred to as

166 'legacy' markers) to better connect sequence datasets produced by targeted amplicon sequencing 167 approaches (Bybee et al. 2011). Several of these widely used markers were already included as

168 part of the "paralogy-tested" 1,105 exons from Hughes et al. (2018), including RAG1 (Lopez et 169 al. 2004), RAG2 (Lovejoy et al. 2004), FICD (Li et al. 2011), PANX2, GCS1, GLYT (Li et al.

170 2007), VCPIP (Betancur-R. et al. 2013), and MLL (Dettai \& Lecointre 2005). A total of 19

171 additional legacy markers that did not meet the paralogy filtering requirements were nonetheless

172 included in the probe sets, mainly markers developed by the Euteleost Tree of Life Project:

173 TBR1, MYH6, KIAA1239, PLAGL2, BTCHD1, RIPK4, SH3PX3, SIDKEY, SREB2, ZIC1,

174 SVEP1, GPR61, SLC10A3, UBE3A, and UBE3A-like (Li et al. 2007, 2011; Betancur-R. et al.

175 2013). Additionally, baits were designed for the markers Rhodopsin (Chen et al. 2003), IRBP

176 (Dettaï \& Lecointre 2008), and RNF213 (Li et al. 2009a), which have been widely used in fish

177 systematics. Due to the long sequences of MYH6 and KIAA1239 (>3,000 bp), references for

178 these markers were shortened to the region typically amplified by PCR primers. The reference

179 sequences used in bait design are available on GitHub

180 (https://github.com/lilychughes/FishLifeExonCapture/tree/master/ProbeSets).

182 Probe sequences of 120 bp in length were initially generated with the py_tiler.py script packaged 183 in PHYLUCE for each of the four to eight taxa selected for probe design (Table 1) (Faircloth et 
184 al. 2012; Faircloth 2015). Probes were mapped against the consensus sequences of the

185 alignments from Hughes et al. (2018) in Geneious Pro v8.1 (http://www.geneious.com) to

186 examine the distribution of probes across loci. Visual inspection of the distribution of probes

187 initially revealed highly uneven coverage of probes across longer loci. To have the probes cover

188 the reference alignments more evenly, we applied a staggering strategy by tiling probes every 20

189 bp across the locus for each of the four to eight taxa (Table 1), so that probes from the first

190 species spanned the first 0-120 bp, and probes from the second species spanned from 20-140,

191 and so on. This strategy ultimately improved tiling density and resulted in more even coverage

192 for longer loci in silico. The probe staggering design was generated via custom scripts (Jake Enk,

193 Arbor Biosciences). Probes that had more than 25\% repeats detected on the RepeatMasker.org

194 database were eliminated. Probes were filtered for potential self-hybridization. Each of our eight

195 probe sets was designed with a MyBaits1 custom probe set with approximately 20,000

196 biotinylated probes for each set (Arbor Biosciences, Ann Arbor, Michigan).

\section{Mitochondrial Probes}

199 In addition to exon probes, we designed and synthesized a separate, fish universal bait set to

200 capture four of the most popular mitochondrial DNA (mtDNA) gene markers used in fish

201 systematics: COI (cytochrome c oxidase subunit I), CYTB (cytochrome $b$ ), and 12S and 16S

202 ribosomal DNA. The goal of maintaining separate mtDNA and nDNA probe sets is to equilibrate

203 nDNA/mtDNA sample ratios by applying spiking dilutions of the mtDNA probe set after

204 capturing the exon markers (mtDNA:nDNA dilution ratios $=1: 1000$ ). Probes for these four

205 mtDNA genes were individually designed using mtDNA genomes or single sequences from

206 NCBI that span the diversity of ray-finned fishes (Amia calva, Danio rerio, Elops saurus, 

ansorgii, Salmo trutta, Takifugu vermicularis, and Zeus faber). A total of 7,000 oligonucleotide baits (120 bp long) tiling over the mtDNA genes with 2x density were designed using the

210 py_tiler.py script (Faircloth et al. 2012; Faircloth 2015). We did not target other high-copy genes

211 like 28S rDNA, which may have required an additional probe set and spiking dilution.

\section{Library Preparation and Sequencing}

214 Eight fish species were newly sequenced for each bait set (Table 2; 56 total species sequenced).

215 DNA extractions were performed on the GenePrep (Autogen Inc.) following manufacturer's

216 instructions at the Laboratory of Analytical Biology at the Smithsonian Institution National

217 Museum of Natural History in Washington, D.C. DNA was eluted in $50 \mu \mathrm{L}$ of Autogen R9

218 Buffer. Quality control was performed by running $1 \mu \mathrm{L}$ of eluted DNA on a $1.0 \%$ agarose gel

219 stained with GelRed (Biotium) and visually inspecting whether bands of high molecular weight

220 DNA were visible. Library preparation was performed at Arbor Biosciences in Ann Arbor,

221 Michigan, using a dual-round capture protocol (Li et al. 2013), with an 8-plex capture design.

222 Paired-end sequencing of 100 bp reads was performed at the University of Chicago Genomics

223 Facility on a HiSeq 4000. Samples were multiplexed with 192 in a lane, with sequencing runs

224 containing samples for other projects not used here.

\section{Bioinformatics Pipeline for Exon Assembly}

227 We developed a bioinformatics pipeline based around the software aTRAM 2.0 (Allen et al.

228 2017) with five major steps before multiple sequence alignment (Figure 4). Raw FASTQ files

229 were quality trimmed with Trimmomatic v0.36 (Bolger et al. 2014), removing low quality 
230 sequences and adapter contamination with the parameters "ILLUMINACLIP:TruSeq3-

231 PE.fa:2:30:10 LEADING:5 TRAILING:5 SLIDINGWINDOW:4:15 MINLEN:31”. Trimmed

232 reads were then mapped against a master file containing all sequences used for bait design for

233 any of the seven probe sets using BWA-MEM (Li \& Durbin 2009). SAMtools v1.8 was used to

234 remove optical PCR duplicates and separate the reads that mapped to each of the exons (Li et al.

235 2009b). Mapped reads were then assembled individually by exon using Velvet (Zerbino \&

236 Birney 2008), and the longest contig produced by Velvet was used as a reference sequence for

237 aTRAM v2.0 (Allen et al. 2017) to extend contigs, using Trinity v2.8.5 as the assembler

238 (Grabherr et al. 2011). Redundant contigs with 100\% identity produced by aTRAM were

239 removed with CD-HIT v4.8.1 using CD-HIT-EST (Li \& Godzik 2006; Fu et al. 2012). Open

240 reading frames for remaining contigs were identified with Exonerate (Slater \& Birney 2005),

241 using a reference sequence checked by eye for each exon, and any contigs that did not contain

242 the open reading frame were filtered out. If only a single contig contained the open reading

243 frame, the exon passed all filters and was used for multiple sequence alignment. If multiple

244 contigs contained the open reading frame, the reading frames were compared with CD-HIT-EST,

245 using a 99\% identity threshold to account for potential allelic variation. If the comparison with

246 CD-HIT-EST resulted in a single contig, that contig passed filters and was used for phylogenetic

247 analysis; more divergent sequences were flagged and excluded from downstream analysis.

248 Unlike another tool recently published to assemble exon-capture data, ASSEXON (Yuan et al.

249 2019), our pipeline is fully automated and does not require Geneious as part of the assembly

250 (https://github.com/lilychughes/FishLifeExonCapture).

252 Alignment and Phylogenomic Analysis 
253 Target-capture data were combined with genomic and transcriptomic data from Hughes et al.

254 (2018), and 36 additional recently published genomes that were mined for orthologous exon

255 sequences using nhmmer (Wheeler \& Eddy 2013). Sequences for each exon were aligned with

256 MACSE v2.03 (Ranwez et al. 2018) after cleaning out potentially non-homologous fragments

257 with the -cleanNonHomologousSequences option. Alignment edges composed of more than $60 \%$

258 missing data as well as insertions that occurred only in a single taxon were removed with custom

259 scripts (AlignmentCleaner.py, https://github.com/lilychughes/FishLifeExonCapture). A total of

2601,104 nuclear exons filtered for paralogs were concatenated using geneStitcher.py

261 (https://github.com/ballesterus/Utensils).

263 A concatenated protein matrix was analyzed under maximum likelihood (ML) with IQ-TREE

264 v1.6.9 (Nguyen et al. 2015), using the best-fitting model for the entire matrix as determined

265 using ModelFinder (Kalyaanamoorthy et al. 2017). A concatenated nucleotide matrix was

266 partitioned into first, second, and third codon positions, with the best-fitting model applied to

267 each partition. Concatenated matrices used contained only the 1,104 loci that have been filtered

268 for paralogy; the legacy markers that failed to pass this filter in Hughes et al. (2018) were

269 excluded from these analyses.

271 Paralogs in Legacy Markers

272 Eighteen nuclear markers that have been commonly used with Sanger sequencing methods for

273 fish phylogenetics were re-included in our probes to better connect novel sequence capture data

274 with extensive existing datasets, but these genes had been previously filtered out for suspected

275 paralogs. For the 18 legacy markers that were re-included (TBR1, MYH6, KIAA1239, PLAGL2, 
PTCHD1, RIPK4, SH3PX3, SIDKEY, SREB2, ZIC1, SVEP1, GPR61, IRBP, RNF213,

277 Rhodopsin, SLC10A3, UBE3A, and UBE3A-like), we integrated our newly sequenced data with

278 the matrices from Betancur-R. et al. (2013) for TBR1, MYH6, KIAA1239, PLAGL2, PTCHD1,

279 RIPK4, SH3PX3, SIDKEY, SREB2, ZIC1. For the remaining genes, we pulled a selection of

280 sequences from GenBank for SVEP1, GPR61, IRBP, RNF213, Rhodopsin, SLC10A3, UBE3A,

281 and UBE3A-like to align with our new data. All GenBank accession numbers can be found on

282 the sequence labels of these gene trees available on FigShare (Hughes et al. 2020). We inferred

283 gene trees in IQ-TREE 1.6.9, partitioning by codon position and using the ModelFinder

284 algorithm to determine the best-fitting sequence model. Target-capture-derived sequences falling

285 out in unexpected positions or clades were BLASTed against the NCBI nucleotide database to

286 determine their identity.

288 Results

289 Capture Efficiency of Nuclear Exons

290 The number of reads per sample varied substantially, from 216,271 to 7,017,309 (Table 2).

291 However, the number of reads per sample was not correlated with the number of loci assembled

292 per species $\left(r^{2}=0.0043 ; p=0.27\right)$. Capture efficiency (measured as the average number of exons

293 assembled per species) varied across probe sets and across samples (Figure 5A), showing a

294 strong negative correlation with clade (or paraphyletic "grade") age $\left(\mathrm{r}^{2}=0.82 ; p=0.003131\right.$;

295 Figure 5B). Two probe sets designed to capture markers in paraphyletic groups that include more 296 anciently diverging lineages ( 251-144 Ma) with larger phylogenetic diversity (Backbone 1 and

297 2; Figures 1-2) tended to have lower capture efficiency (Table 2; Figure 5A), with an average of

$29852 \%$ of the loci captured for Backbone 1 and $61 \%$ on average captured for Backbone 2. This was 
299 also the case for the rather ancient Elopomorpha clade (196 Ma), for which samples sequenced

300 had only a $60 \%$ capture rate. Probe sets designed for more recently diverged percomorph clades

301 ( 105-66 Ma) had much higher numbers of loci assembled on average, with 83\% for Carangaria,

$30282 \%$ for Ovalentaria, $81 \%$ for Eupercaria, and $89 \%$ for the Syngnatharia + Pelagiaria clade.

303 Probe sets are publicly available at Arbor Biosciences, Ann Arbor, MI. Exon alignments ranged

304 from a minimum of $60 \%$ up to $93.9 \%$ sequence identity across the eight model genomes

305 originally used to discover single-copy markers, but the legacy markers tended to have $>80 \%$

306 sequence identity (Figure 5C).

307

308

Mitochondrial Gene Capture

309 Mitochondrial genes for which we designed probes (12S, 16S, COI, ATPase6, and CYTB)

310 tended to have the best rate of capture. Complete sequences of $12 \mathrm{~S}, 16 \mathrm{~S}$, and COI assembled for

311 all taxa, while ND6, for which we did not design probes, was only represented for 29 taxa, the

312 lowest of any mitochondrial coding gene. CYTB, which was included in the probe set,

313 assembled for 56 of 58 total taxa, but ATPase6 had a relatively poor capture rate, only

314 assembling for 36 species.

316 Phylogenomic Analysis

317 Combining the new data for 56 samples collected through exon-capture plus 38 additional

318 recently published fish genomes with the dataset of Hughes et al. (2018) generated a matrix with

319394 taxa representing all major groups of ray-finned fishes with three lobe-finned

320 (sarcopterygian) outgroups, with a final length of 549,861 bp (183,287 amino acid sites). The

321 entire matrix had $72 \%$ present data, excluding loci suspected of having paralogs (Table 3 ). The 
322 average locus alignment length for genes included in the matrix was 499 bp (range: 129-5,055

$323 \mathrm{bp}$ ), and the average number of parsimony-informative sites per locus was 340 (range: 75-3,435).

325 ModelFinder selected JTT+I+F+G for the protein matrix, and GTR $+\mathrm{I}+\mathrm{F}+\mathrm{G}$ for the first two

326 codon positions, with TVM+I+F+G for the third codon position. Both topologies inferred with

327 IQ-TREE matched previous results obtained by Hughes et al. (2018), with newly added taxa

328 placed in their expected phylogenetic placements (Figures 1-3). Tree files and phylogenomic

329 matrices are available on FigShare (Hughes et al. 2020).

$331 \quad$ Paralogs in Legacy Markers

332 We examined gene trees by eye for evidence paralogs had been assembled for 19 markers that

333 were included in our probe set, despite failing previous tests to exclude loci with paralogs. Nine

334 of these loci assembled one or more paralogs when we applied our new pipeline on the raw reads

335 obtained with sequence capture instead of a single orthologous locus (Table 3). One locus

336 (PTCHD1) could only be assembled for seven of the 56 newly sequenced samples, which made

337 the paralogy assessment difficult. Annotation of the paralogous sequences was determined by

338 blasting assembled contigs against the NCBI nucleotide database.

340 Discussion

341 Deep Probe Sets Capture Across Deep Phylogenetic Divergences

342 We present resources for capturing conserved exon sequences for all groups of teleost fishes,

343 including probe sets for early branching lineages ("Backbone 1”), Elopomorpha,

344 Acanthomorphata ("Backbone 2"), and multiple major percomorph radiations including 
345 Syngnatharia + Pelagiaria, Carangaria, Ovalentaria, and Eupercaria. The exon markers presented

346 here have been explicitly tested for orthology using a large database of 303 bony fish species

347 (Hughes et al. 2018), and have been screened for paralogs derived from ancient vertebrate or

348 teleost-specific whole genome duplication events. Capture efficiency is strongly correlated with

349 the phylogenetic span of taxa used to design the probes, with probe sets designed more

350 specifically for younger ( 105-66 Ma) percomorph clades (Syngnatharia-Pelagiaria, Carangaria,

351 Ovalentaria, Eupercaria) capturing 200-300 more loci on average than those designed for more

352 ancient ( 251-144 Ma) and/or taxonomically disparate clades (Elopomorpha and Backbones 1

353 and 2; Figure 5B). Estimates for the divergence times of major percomorph series vary, but the

354 youngest estimates place their origin near the Cretaceous-Paleogene boundary, 66 million years

355 ago (Alfaro et al. 2018). Conversely, the paraphyletic taxonomic groups spanned by Backbone 1

356 diverged in the Permian or Triassic, and the late Jurassic to early Cretaceous for Backbone 2

357 (Betancur-R. et al. 2013; Near et al. 2013a; Hughes et al. 2018). The larger number of nucleotide

358 substitutions accumulated across older clades causes the probes to have less affinity for the

359 targeted DNA regions in vitro, and we noticed a substantial increase in the number of loci

360 captured for those clades younger than 100 million years (Figure 5B). One way to improve

361 capture efficiency for particular projects would be to select more closely related taxa to design a

362 new (more specific) probe set.

363

364 Despite the variation in the number of loci assembled, all samples with exon-capture data were

365 resolved in their expected clades, and the ML topologies at major nodes matched that of the ML

366 topologies of Hughes et al. (2018). One family, Clupeidae, was not monophyletic, but this result

367 has been reported before in previous phylogenetic analyses (Betancur-R et al. 2017), and may 
368 reflect the need of taxonomic revision or poor taxonomic sampling rather than underlying

369 phylogenetic estimation error arising from the exon-capture data. These markers appear to be

370 informative for deep divergences in fishes, and the backbone of the ray-finned fish tree largely

371 matches inferences based on legacy gene markers (Near et al. 2012; Betancur-R. et al. 2013),

372 though many areas of the tree have only been investigated with sparse taxonomic sampling and

373 will require more thorough investigation with additional sequencing. While deep divergences are

374 the focus of this paper, conserved exon markers have also been shown to contain information

375 appropriate for shallower divergences at the phylogeographic level (Rincon-Sandoval et al.

376 2019). The flanking intron regions, which are highly variable, have been removed for the

377 analyses presented here, but we include a branch of our bioinformatic pipeline to additionally use

378 the flanking intron sequences for projects with a more recent evolutionary focus.

380 Exon markers can be integrated with existing and future datasets

381 Taxonomic sampling is critical for accurate phylogenetic analysis (Heath et al. 2008;

382 Betancur-R. et al. 2019), and sequence capture methods are a cost-effective approach for

383 increasing taxonomic sampling across a large number of loci (Lemmon \& Lemmon 2013). But

384 both whole-genome sequences (Malmstrøm et al. 2016; Musilova et al. 2019) and transcriptome

385 sequences (e.g. Hughes et al. 2018; Dai et al. 2018) are becoming available for an increasing

386 diversity of fish species. These exon markers can be easily mined from public transcriptome or

387 genome data as they become available, increasing taxonomic sampling for the group of interest

388 without duplicating sequencing effort. Taxonomically dense super-matrix approaches in fishes

389 (e.g. Rabosky et al. 2018) primarily rely on exon sequences deposited in NCBI. Currently, there

390 are more than 20,000 sequences of RAG1 for teleosts available in NCBI (as of March 20, 2019), 
more than 35,000 teleost rhodopsin sequences, and even larger numbers for mitochondrial genes

like CYTB (>130,000 sequences). This is a rich resource that can be combined with exoncapture data for the probe sets described here to reduce missing data that are often rampant in

394 super matrix approaches but still produce taxonomically dense trees.

\section{Paralogs in sequence capture datasets}

397 Many nuclear exon fragments that have been in wide use in fish phylogenetics for more than a

398 decade do not appear to have paralogs, and new sequence capture data could be easily integrated

399 from genes like RAG1, RAG2, PANX2, MLL, VCPIP, GLYT, GCS1, and FICD. Many of these

400 exons were defined as 'single-copy' based on the comparisons of the relatively few fish genomes

401 available at the time (Li et al. 2007). But the specificity of primers designed for nested PCR

402 approaches to amplify and sequence these loci has been a successful strategy to obtain

403 orthologous genes for phylogenetic inference in fishes (Li et al. 2007, 2008, 2010; Near et al.

404 2012, 2013b; Wainwright et al. 2012; Betancur-R. et al. 2013). Shotgun sequencing of enriched

405 libraries, in contrast, is a more challenging approach for assembling orthologous genes, since

406 sequence reads of two or more paralogous copies may be sequenced by this approach and need to

407 be separated using bioinformatic pipelines. Nineteen legacy markers included in our probe set

408 previously had been excluded from downstream phylogenetic analyses due to paralogy issues

409 detected either by comparing additional genomes or by topology tests of gene trees (Table 3).

410 Due to high similarity in certain parts of the coding region to the reference coding sequence used

411 in Exonerate, more than half of these assembled paralogous loci passed through to the alignment

412 stage. Often it was only the paralog that was assembled, and the assembly of multiple contigs

413 was not a reliable way to flag paralogy. The pipeline implemented here (Figure 4) attempts to 
remove redundant contigs with CD-HIT at a $99 \%$ similarity threshold across the reading frame

415 when multiple contigs assemble, but exons that fail this test are not passed onto the alignment

416 stage. Paralogs of ENC1, MYH6, ZIC1 and other genes known to be duplicated (Table 3) passed

417 on to the alignment stage, and do not appear to have assembled the orthologous sequence.

418 However, a majority of the sequences assembled orthologous exons. With additional scrutiny for

419 paralogs using gene trees, these data are still quite useful for integration with older datasets.

420

421

422

423

424

425

426

427

428

429

430

431

432

433

434

435

436

437

438

439

440

441

442

443

444

445

446

447

448

449

450

451

452

453

\section{Acknowledgements}

This research was supported by National Science Foundation (NSF) grants NSF-DEB-1929248 and NSF-DEB-1932759 to R.B.R., NSF-DEB-1541554 and NSF-DEB-1457426 to G.O., and NSF-DEB-1541552 to C.C.B. We are grateful to Jake Enk (Arbor Biosciences) for his assistance with probe design. We thank Rose Peterson and Victoria Rodriguez for assistance with laboratory work, and Diane Pitassy for access to tissues at the USNM. All data processing and phylogenetic analysis were conducted on the Pegasus HPC cluster at George Washington University.

\section{References}

Abascal F, Zardoya R, Telford MJ (2010) TranslatorX: multiple alignment of nucleotide sequences guided by amino acid translations. Nucleic Acids Research, 38, W7-W13.

Alfaro ME, Faircloth BC, Harrington RC et al. (2018) Explosive diversification of marine fishes at the Cretaceous-Palaeogene boundary. Nature Ecology \& Evolution.

Allen JM, Boyd B, Nguyen N et al. (2017) Phylogenomics from Whole Genome Sequences Using aTRAM. Systematic Biology, 66, 786-798.

Arcila D, Ortí G, Vari R et al. (2017) Genome-wide interrogation advances resolution of recalcitrant groups in the tree of life. Nature Ecology \& Evolution, 1, 0020.

Betancur-R. R, Broughton RE, Wiley EO et al. (2013) The Tree of Life and a New Classification of Bony Fishes. PLoS Currents, 5.

Betancur-R R, Orti G, O Wiley E et al. (2017) Phylogenetic classification of bony fishes. BMC Evolutionary Biology, 1-40.

Betancur-R. R, Arcila D, Vari RP et al. (2019) Phylogenomic incongruence, hypothesis testing, and taxonomic sampling: The monophyly of characiform fishes. Evolution, 73, 329-345.

Bolger AM, Lohse M, Usadel B (2014) Trimmomatic: a flexible trimmer for Illumina sequence data. Bioinformatics, 30, 2114-2120.

Braasch I, Peterson SM, Desvignes T et al. (2015) A new model army: Emerging fish models to study the genomics of vertebrate Evo-Devo. Journal of Experimental Zoology Part B: Molecular and Developmental Evolution, 324, 316-341.

Bybee SM, Bracken-Grissom H, Haynes BD et al. (2011) Targeted Amplicon Sequencing (TAS): A Scalable Next-Gen Approach to Multilocus, Multitaxa Phylogenetics. Genome Biology and Evolution, 3, 1312-1323. 
Chakrabarty P, Faircloth BC, Alda F et al. (2017) Phylogenomic Systematics of Ostariophysan Fishes: Ultraconserved Elements Support the Surprising Non-Monophyly of Characiformes. Systematic Biology, 66, 881-895.

Chen W-J, Bonillo C, Lecointre G (2003) Repeatability of clades as a criterion of reliability: a case study for molecular phylogeny of Acanthomorpha (Teleostei) with larger number of taxa. Molecular Phylogenetics and Evolution, 26, 262-288.

Dai W, Zou M, Yang L et al. (2018) Phylogenomic Perspective on the Relationships and Evolutionary History of the Major Otocephalan Lineages. Scientific Reports, 8, 205.

Dehal P, Boore JL (2005) Two Rounds of Whole Genome Duplication in the Ancestral Vertebrate (P Holland, Ed,). PLoS Biology, 3, e314.

Dettai A, Lecointre G (2005) Further support for the clades obtained by multiple molecular phylogenies in the acanthomorph bush. Comptes Rendus - Biologies, 328, 674-689.

Dettaï A, Lecointre G (2008) New insights into the organization and evolution of vertebrate IRBP genes and utility of IRBP gene sequences for the phylogenetic study of the Acanthomorpha (Actinopterygii: Teleostei). Molecular Phylogenetics and Evolution, 48, 258-269.

Dornburg A, Townsend JP, Brooks W et al. (2017) New Insights on the Sister Lineage of Percomorph Fishes with an Anchored Hybrid Enrichment Dataset. Molecular Phylogenetics and Evolution, 110, 27-38.

Edwards S V., Cloutier A, Baker AJ (2017) Conserved Nonexonic Elements: A Novel Class of Marker for Phylogenomics. Systematic Biology, 66, 1028-1044.

Eytan RI, Evans BR, Dornburg A et al. (2015) Are 100 enough? Inferring acanthomorph teleost phylogeny using Anchored Hybrid Enrichment. BMC evolutionary biology, 15, 113.

Faircloth BC (2015) PHYLUCE is a software package for the analysis of conserved genomic loci. Bioinformatics, 32, 786-788.

Faircloth BC, Alda F, Hoekzema K et al. (2020) A target enrichment bait set for studying relationships among ostariophysan fishes. Copeia, 108, 47-60.

Faircloth BC, McCormack JE, Crawford NG et al. (2012) Ultraconserved elements anchor thousands of genetic markers spanning multiple evolutionary timescales. Systematic Biology, 61, 717-726.

Faircloth BC, Sorenson L, Santini F, Alfaro ME (2013) A Phylogenomic Perspective on the Radiation of Ray-Finned Fishes Based upon Targeted Sequencing of Ultraconserved Elements (UCEs). PLoS One, 8, e65923.

Friedman M, Feilich KL, Beckett HT et al. (2019) A phylogenomic framework for pelagiarian fishes (Acanthomorpha: Percomorpha) highlights mosaic radiation in the open ocean. Proceedings of the Royal Society B: Biological Sciences, 286, 20191502.

Fu L, Niu B, Zhu Z, Wu S, Li W (2012) CD-HIT: accelerated for clustering the next-generation sequencing data. Bioinformatics, 28, 3150-3152.

Grabherr MG, Haas BJ, Yassour M et al. (2011) Full-length transcriptome assembly from RNASeq data without a reference genome. Nature biotechnology, 29, 644-652.

Harrington RC, Faircloth BC, Eytan RI et al. (2016) Phylogenomic analysis of carangimorph fishes reveals flatfish asymmetry arose in a blink of the evolutionary eye. $B M C$ Evolutionary Biology, 16, 224.

Heath TA, Hedtke SM, Hillis DM (2008) Taxon sampling and the accuracy of phylogenetic analyses. Journal of Systematics And Evolution, 46, 239-257.

Hughes LC, Ortí G, Huang Y et al. (2018) Comprehensive phylogeny of ray-finned fishes 
(Actinopterygii) based on transcriptomic and genomic data. Proceedings of the National Academy of Sciences, 115, 6249-6254.

Hughes LC, Ortí G, Saad H et al. (2020) Data from: Exon probe sets and bioinformatics pipelines for all levels of fish phylogenomics. FigShare, doi:10.6084/m9.figshare.11844783.

Ilves KL, López-Fernández H (2014) A targeted next-generation sequencing toolkit for exonbased cichlid phylogenomics. Molecular Ecology Resources, 14, 802-811.

Ilves KL, Torti D, López-Fernández H (2017) Exon-based phylogenomics strengthens the phylogeny of Neotropical cichlids and identifies remaining conflicting clades (Cichliformes: Cichlidae: Cichlinae). Molecular Phylogenetics and Evolution, 118, 232243.

Inoue J, Sato Y, Sinclair R, Tsukamoto K, Nishida M (2015) Rapid genome reshaping by multiple-gene loss after whole-genome duplication in teleost fish suggested by mathematical modeling. Proceedings of the National Academy of Sciences, 112, 1491814923.

Irisarri I, Singh P, Koblmüller S et al. (2018) Phylogenomics uncovers early hybridization and adaptive loci shaping the radiation of Lake Tanganyika cichlid fishes. Nature Communications, 9, 3159.

Jiang J, Yuan H, Zheng X et al. (2019) Gene markers for exon capture and phylogenomics in ray-finned fishes. Ecology and Evolution, 9, 3973-3983.

Kalyaanamoorthy S, Minh BQ, Wong TKF, von Haeseler A, Jermiin LS (2017) ModelFinder: fast model selection for accurate phylogenetic estimates. Nature Methods, 14, 587-589.

Kuang T, Tornabene L, Li J et al. (2018) Phylogenomic analysis on the exceptionally diverse fish clade Gobioidei (Actinopterygii: Gobiiformes) and data-filtering based on molecular clocklikeness. Molecular Phylogenetics and Evolution, 128, 192-202.

Lemmon AR, Emme SA, Lemmon EM (2012) Anchored Hybrid Enrichment for Massively High-Throughput Phylogenomics. Systematic Biology, 61, 727-744.

Lemmon EM, Lemmon AR (2013) High-Throughput Genomic Data in Systematics and Phylogenetics. Annual Review of Ecology, Evolution, and Systematics, 44, 99-121.

Li C, Corrigan S, Yang L et al. (2015) DNA capture reveals transoceanic gene flow in endangered river sharks. Proceedings of the National Academy of Sciences, 112, 1330213307.

Li B, Dettaï A, Cruaud C et al. (2009a) RNF213, a new nuclear marker for acanthomorph phylogeny. Molecular Phylogenetics and Evolution, 50, 345-363.

Li H, Durbin R (2009) Fast and accurate short read alignment with Burrows-Wheeler transform. Bioinformatics, 25, 1754-1760.

Li W, Godzik A (2006) Cd-hit: a fast program for clustering and comparing large sets of protein or nucleotide sequences. Bioinformatics, 22, 1658-1659.

Li H, Handsaker B, Wysoker A et al. (2009b) The Sequence Alignment/Map format and SAMtools. Bioinformatics, 25, 2078-2079.

Li C, Hofreiter M, Straube N, Corrigan S, Naylor GJP (2013) Capturing protein-coding genes across highly divergent species. BioTechniques, 54, 321-326.

Li C, Lu G, Ortí G (2008) Optimal Data Partitioning and a Test Case for Ray-Finned Fishes (Actinopterygii) Based on Ten Nuclear Loci (T Buckley, Ed,). Systematic Biology, 57, 519539.

Li C, Ortí G, Zhang G, Lu G (2007) A practical approach to phylogenomics: the phylogeny of 
ray-finned fish (Actinopterygii) as a case study. BMC Evolutionary Biology, 7, 44.

Li C, Ortí G, Zhao J (2010) The phylogenetic placement of sinipercid fishes ("Perciformes") revealed by 11 nuclear loci. Molecular Phylogenetics and Evolution, 56, 1096-1104.

Li C, Ricardo B-R, Leo Smith W, Ortí G (2011) Monophyly and interrelationships of Snook and Barramundi (Centropomidae sensu Greenwood) and five new markers for fish phylogenetics. Molecular Phylogenetics and Evolution, 60, 463-471.

Li C, Riethoven JJM, Naylor GJP (2012) EvolMarkers: A database for mining exon and intron markers for evolution, ecology and conservation studies. Molecular Ecology Resources, 12, 967-971.

Longo SJ, Faircloth BC, Meyer A et al. (2017) Phylogenomic analysis of a rapid radiation of misfit fishes (Syngnathiformes) using ultraconserved elements. Molecular Phylogenetics and Evolution, 113, 33-48.

Lopez JA, Chen W-J, Ortí G (2004) Esociform Phylogeny. Copeia, 3, 449-464.

Lovejoy NR, Iranpour M, Collette BB (2004) Phylogeny and jaw ontogeny of beloniform fishes. Integrative and Comparative Biology, 44, 366-377.

Malmstrøm M, Matschiner M, Tørresen OK et al. (2016) Evolution of the immune system influences speciation rates in teleost fishes. Nature Genetics, 48, 1204-1210.

Musilova Z, Cortesi F, Matschiner M et al. (2019) Vision using multiple distinct rod opsins in deep-sea fishes. Science, 364, 588-592.

Near TJ, Dornburg A, Eytan RI et al. (2013a) Phylogeny and tempo of diversification in the superradiation of spiny-rayed fishes. Proceedings of the National Academy of Sciences, 110, $12738-12743$.

Near TJ, Dornburg A, Eytan RI et al. (2013b) Phylogeny and tempo of diversification in the superradiation of spiny-rayed fishes. Proceedings of the National Academy of Sciences, 110, 12738-12743.

Near TJ, Eytan RI, Dornburg A et al. (2012) Resolution of ray-finned fish phylogeny and timing of diversification. Proceedings of the National Academy of Sciences, 109, 13698-13703.

Nguyen LT, Schmidt HA, Von Haeseler A, Minh BQ (2015) IQ-TREE: A fast and effective stochastic algorithm for estimating maximum-likelihood phylogenies. Molecular Biology and Evolution, 32, 268-274.

Rabosky DL, Chang J, Title PO et al. (2018) An inverse latitudinal gradient in speciation rate for marine fishes. Nature, 559, 392-395.

Ranwez V, Douzery EJP, Cambon C, Chantret N, Delsuc F (2018) MACSE v2: Toolkit for the Alignment of Coding Sequences Accounting for Frameshifts and Stop Codons. Molecular biology and evolution, 35, 2582-2584.

Ranwez V, Harispe S, Delsuc F, Douzery EJP (2011) MACSE: Multiple alignment of coding SEquences accounting for frameshifts and stop codons. PLOS ONE, 6.

Rincon-Sandoval M, Betancur-R R, Maldonado-Ocampo JA (2019) Comparative phylogeography of trans-Andean freshwater fishes based on genome-wide nuclear and mitochondrial markers. Molecular Ecology, 28, 1096-1115.

Roxo FF, Ochoa LE, Sabaj MH et al. (2019) Phylogenomic reappraisal of the Neotropical catfish family Loricariidae (Teleostei: Siluriformes) using ultraconserved elements. Molecular Phylogenetics and Evolution, 135, 148-165.

Slater GSC, Birney E (2005) Automated generation of heuristics for biological sequence comparison. BMC Bioinformatics, 6, 1-11.

Song S, Zhao J, Li C (2017) Species delimitation and phylogenetic reconstruction of the 
sinipercids (Perciformes: Sinipercidae) based on target enrichment of thousands of nuclear coding sequences. Molecular Phylogenetics and Evolution, 111, 44-55.

Stout CC, Tan M, Lemmon AR, Lemmon EM, Armbruster JW (2016) Resolving Cypriniformes relationships using an anchored enrichment approach. BMC Evolutionary Biology, 16, 244.

Straube N, Li C, Mertzen M, Yuan H, Moritz T (2018) A phylogenomic approach to reconstruct interrelationships of main clupeocephalan lineages with a critical discussion of morphological apomorphies. BMC Evolutionary Biology, 18, 158.

Sun Y, Huang Y, Li X et al. (2016) Fish-T1K (Transcriptomes of 1,000 Fishes) Project: largescale transcriptome data for fish evolution studies. GigaScience, 5, 18.

Vandepoele K, De Vos W, Taylor JS, Meyer A, Van de Peer Y (2004) Major events in the genome evolution of vertebrates: Paranome age and size differ considerably between rayfinned fishes and land vertebrates. Proceedings of the National Academy of Sciences, 101, 1638-1643.

Wainwright PC, Smith WL, Price SA et al. (2012) The Evolution of Pharyngognathy: A Phylogenetic and Functional Appraisal of the Pharyngeal Jaw Key Innovation in Labroid Fishes and Beyond. Systematic Biology, 61, 1001-1027.

Wheeler TJ, Eddy SR (2013) nhmmer: DNA homology search with profile HMMs. Bioinformatics, 29, 2487-2489.

Yin G, Pan Y, Sarker A et al. (2019) Molecular systematics of Pampus (Perciformes:

Stromateidae) based on thousands of nuclear loci using target-gene enrichment. Molecular Phylogenetics and Evolution, 140, 106595.

Yuan H, Atta C, Tornabene L, Li C (2019) Assexon: Assembling Exon Using Gene Capture Data. Evolutionary Bioinformatics, 15, 117693431987479.

Zerbino DR, Birney E (2008) Velvet: Algorithms for de novo short read assembly using de Bruijn graphs. Genome Research, 18, 821-829.

\section{Data Accessibility}

Raw reads for newly sequenced exon-capture data are archived on NCBI under Bioproject number PRJNA605876. Newick files and phylogenomic matrices are available on FigShare (doi: 10.6084/m9.figshare.11844783), and pipeline scripts to analyze data and a tutorial are available on GitHub (https://github.com/lilychughes/FishLifeExonCapture). The protein tree topology will be made available on Open Tree of Life.

\section{Author Contributions}

L.C.H., R.B-R., G.O., K.A.C, C.L., and D.A. contributed to the design of the study. R.B-R., C.C.B., and W.W. provided tissues. L.C.H., H.S., C.L., and R.B-R. analyzed the data. L.C.H., G.O., and R.B-R. wrote the paper with input from all authors.

Table 1. Seven probe sets designed for 1,104 conserved exon markers across teleost fishes.

\begin{tabular}{ll}
\hline Probe Set Name & Lineages Included (Preferred lineage in bold) \\
\hline Elopomorpha & 1. Megalopidae \\
& 2. Muraenidae \\
& 3. Congridae, Chlopsidae \\
& 4. Anguillidae \\
\hline Backbone 1 & 1. Osteoglossidae, Pantodontidae \\
& 2. Notopteridae, Mormyridae \\
\hline
\end{tabular}




\begin{tabular}{|c|c|}
\hline & $\begin{array}{l}\text { 3. Engraulidae, Clupeidae } \\
\text { 4. Galaxiidae } \\
\text { 5. Argentinidae } \\
\text { 6. Stomiidae, Osmeridae, Plecoglossidae, Salangidae } \\
\text { 7. Synodontidae, Chlorophthalmidae } \\
\text { 8. Myctophidae }\end{array}$ \\
\hline Backbone 2 & $\begin{array}{l}\text { 1. Zeidae, Parazenidae } \\
\text { 2. Berycidae, Stephanoberycidae, Rondeletiidae } \\
\text { 3. Holocentridae } \\
\text { 4. Ophidiidae } \\
\text { 5. Apogonidae } \\
\text { 6. Gobiidae } \\
\text { 7. Synbranchiformes, Anabantiformes }\end{array}$ \\
\hline Syngnatharia-Pelagiaria & $\begin{array}{l}\text { 1. Syngnathidae, Callionymidae } \\
\text { 2. Mullidae, Aulostomidae } \\
\text { 3. Scombridae } \\
\text { 4. Nomeidae, Stromateidae }\end{array}$ \\
\hline Carangaria & $\begin{array}{l}\text { 1. Coryphaenidae, Carangidae } \\
\text { 2. Cynoglossidae, Paralichthyidae, Pleuronectidae, } \\
\text { Scophthalmidae, Soleidae } \\
\text { 3. Centropomidae } \\
\text { 4. Polynemidae, Toxotidae }\end{array}$ \\
\hline Ovalentaria & $\begin{array}{l}\text { 1. Pseudomugilidae, Melanotaeniidae, Atherinopsidae } \\
\text { 2. Aplocheilidae, Nothobranchiidae, Rivulidae, Cyprinodontidae, } \\
\text { Fundulidae, Poeciliidae } \\
\text { 3. Tripterygiidae, Blenniidae, Chaenopsidae } \\
\text { 4. Gobiesocidae } \\
\text { 5. Pomacentridae }\end{array}$ \\
\hline Eupercaria & $\begin{array}{l}\text { 1. Anoplopomatidae, Channichthydae, Cottidae, Gasterosteidae, } \\
\text { Nototheniidae, Bathydraconidae, Percidae, Sebastidae } \\
\text { 2. Gerreidae, Labridae, Scaridae, Pinguipedidae, Lateolabracidae, } \\
\text { Epigonidae } \\
\text { 3. Tetraodontidae, Molidae, Chaunacidae, Caproidae, Diodontidae, } \\
\text { Antennariidae, Balistidae, Acanthuridae } \\
\text { 4. Lutjanidae, Haemulidae, Chaetodontidae, Moronidae, Datnioididae, } \\
\text { Ephippidae, Sciaenidae }\end{array}$ \\
\hline
\end{tabular}

634 Table 2. Species sequenced for each probe set and the number of reads and loci assembled.

635 Estimated clade ages (Hughes et al. 2018) are indicated.

\begin{tabular}{llllll}
\hline Probe set & Family & Taxon & Collection No. & $\begin{array}{l}\text { Paired-end } \\
\text { Reads }\end{array}$ & Loci \\
& & & & \\
\hline $\begin{array}{l}\text { Elopomorpha } \\
(196 \mathrm{Ma})\end{array}$ & Albulidae & Albula cf. vulpes & ${ }^{\mathrm{a} U S N M} 421848$ & $1,801,676$ & 642 \\
& Congridae & Conger cinereus & ${ }^{\mathrm{b}}$ CSIRO GT7882 & $3,427,134$ & 731 \\
& Elopidae & Elops hawaiensis & USNM 403422 & $3,020,903$ & 759 \\
& Halosauridae & $\begin{array}{l}\text { Halosaurus } \\
\text { johnsonianus }\end{array}$ & USNM 405058 & $2,034,292$ & 606 \\
& Halosauridae & Halosaurus ovenii & USNM 407039 & $4,743,893$ & 719 \\
& Nettastomatidae & $\begin{array}{l}\text { Nettastoma } \\
\text { parviceps }\end{array}$ & CSIRO GT6156 & $1,127,769$ & 631 \\
& Myrophis & USNM 435225 & $1,362,661$ & 586 \\
& Ophichochir & & & \\
\hline
\end{tabular}




\begin{tabular}{|c|c|c|c|c|c|}
\hline & Synaphobranchidae & Meadia roseni & CSIRO GT6877 & $2,734,565$ & 735 \\
\hline \multirow{8}{*}{$\begin{array}{l}\text { Backbone1 } \\
\text { (251 Ma) }\end{array}$} & Clupeidae & Jenkinsia majua & ${ }^{c}$ UPR FL0045 & $5,391,027$ & 407 \\
\hline & Gonostomatidae & Diplophos taenia & USNM 405007 & $7,017,309$ & 703 \\
\hline & Myctophidae & $\begin{array}{l}\text { Myctophum } \\
\text { nitidulum }\end{array}$ & USNM 405014 & $1,913,709$ & 607 \\
\hline & Neoscopelidae & $\begin{array}{l}\text { Neoscopelus } \\
\text { microchir }\end{array}$ & USNM 407030 & $2,050,980$ & 668 \\
\hline & Osteoglossidae & Arapiama gigas & USNM 440586 & $3,024,165$ & 742 \\
\hline & Sternoptychidae & $\begin{array}{l}\text { Argyripnus } \\
\text { atlanticus }\end{array}$ & USNM 405229 & $2,328,143$ & 651 \\
\hline & Stomiidae & Chauliodus sloani & USNM 405061 & $3,058,984$ & 377 \\
\hline & Synodontidae & Saurida gracilis & ${ }^{\mathrm{d}}$ STRI BFT 11840 & $2,623,498$ & 600 \\
\hline \multirow{8}{*}{$\begin{array}{l}\text { Backbone2 } \\
(144 \mathrm{Ma})\end{array}$} & Apogonidae & Apogon robinsi & UPR FL0162 & 818,383 & 787 \\
\hline & Batrachoididae & Opsanus tau & STRI BFT09764 & 924,435 & 633 \\
\hline & Eleotridae & $\begin{array}{l}\text { Dormitator } \\
\text { latifrons }\end{array}$ & STRI BFT02768 & $1,584,877$ & 671 \\
\hline & Gobiidae & $\begin{array}{l}\text { Ctenogobius } \\
\text { sagittula }\end{array}$ & STRI BFT18404 & $1,525,545$ & 467 \\
\hline & Gobiidae & $\begin{array}{l}\text { Ginsburgellus } \\
\text { novemlineatus }\end{array}$ & UPR FL0141 & $1,265,097$ & 597 \\
\hline & Grammicolepididae & $\begin{array}{l}\text { Xenolepidichthys } \\
\text { dalgleishi }\end{array}$ & USNM 407099 & $3,208,789$ & 788 \\
\hline & Holocentridae & $\begin{array}{l}\text { Plectrypops } \\
\text { retrospinis }\end{array}$ & $\begin{array}{l}\text { UPR FL0166/ } \\
\text { MZUPRRP-I- } \\
00357\end{array}$ & $3,237,186$ & 920 \\
\hline & Synbranchidae & $\begin{array}{l}\text { Synbranchus } \\
\text { marmoratus }\end{array}$ & STRI BFT05012 & $1,762,538$ & 681 \\
\hline \multirow{8}{*}{$\begin{array}{l}\text { Carangaria } \\
(65 \mathrm{Ma})\end{array}$} & Achiridae & Trinectes inscriptus & USNM 414275 & 979,351 & 988 \\
\hline & Carangidae & $\begin{array}{l}\text { Carangoides } \\
\text { armatus }\end{array}$ & USNM 435427 & $1,983,024$ & 1034 \\
\hline & Cynoglossidae & $\begin{array}{l}\text { Cynoglossus } \\
\text { maculipinnis }\end{array}$ & USNM 437669 & $1,387,678$ & 868 \\
\hline & Echeneidae & Remora remora & USNM 405009 & $1,385,700$ & 994 \\
\hline & Pleuronectidae & Microstomus kitt & USNM T5415 & 597,910 & 927 \\
\hline & Rachycentridae & $\begin{array}{l}\text { Rachycentron } \\
\text { canadum }\end{array}$ & USNM T3521 & $1,428,271$ & 1026 \\
\hline & Samaridae & $\begin{array}{l}\text { Samariscus } \\
\text { triocellatus }\end{array}$ & USNM 391219 & 216,271 & 637 \\
\hline & Sphyraenidae & Inegocia japonica & USNM T10332 & $2,968,482$ & 1012 \\
\hline \multirow{8}{*}{$\begin{array}{l}\text { Ovalentaria } \\
(95 \mathrm{Ma})\end{array}$} & Ambassidae & Ambassis nalua & USNM 403430 & $2,666,551$ & 1017 \\
\hline & Atherinidae & $\begin{array}{l}\text { Hypoatherina } \\
\text { panatela }\end{array}$ & USNM 437959 & 945,584 & 878 \\
\hline & Blenniidae & Exallias brevis & USNM 390993 & $2,475,300$ & 920 \\
\hline & Opistognathidae & $\begin{array}{l}\text { Opistognathus } \\
\text { castelnaui }\end{array}$ & USNM 435841 & $1,117,986$ & 840 \\
\hline & Plesiopidae & $\begin{array}{l}\text { Belonepterygion } \\
\text { fasciolatum }\end{array}$ & USNM 432574 & $1,453,409$ & 956 \\
\hline & Poeciliidae & $\begin{array}{l}\text { Phallichthys } \\
\text { fairweatheri }\end{array}$ & STRI BFT06906 & $1,984,926$ & 911 \\
\hline & Pomacentridae & $\begin{array}{l}\text { Microspathodon } \\
\text { chrysurus }\end{array}$ & STRI BFT13594 & $2,156,316$ & 985 \\
\hline & Zenarchopteridae & $\begin{array}{l}\text { Zenarchopterus } \\
\text { dispar }\end{array}$ & STRI BFT07992 & $1,744,848$ & 916 \\
\hline \multirow{2}{*}{$\begin{array}{l}\text { Eupercaria } \\
\text { (105 Ma) }\end{array}$} & Acanthuridae & Acanthurus mata & USNM 403159 & $2,439,554$ & 1005 \\
\hline & Gerreidae & $\begin{array}{l}\text { Eucinostomus } \\
\text { lefroyi }\end{array}$ & $\begin{array}{l}\text { UPR FL0004 / } \\
\text { MZUPRRP-I- }\end{array}$ & $2,257,350$ & 994 \\
\hline
\end{tabular}




\begin{tabular}{|c|c|c|c|c|c|}
\hline & & & 00223 & & \\
\hline & Lutjanidae & Gymnocaesio & USNM 435461 & $1,944,110$ & 953 \\
\hline & Monacanthidae & $\begin{array}{l}\text { gymnoptera } \\
\text { Cantherhines } \\
\text { pardalis }\end{array}$ & USNM 435717 & $3,649,643$ & 788 \\
\hline & Ogcocephalidae & $\begin{array}{l}\text { Halieutichthys } \\
\text { aculeatus }\end{array}$ & USNM 433145 & 930,425 & 765 \\
\hline & Sciaenidae & Pareques & UPR FL0151/ & $1,553,389$ & 948 \\
\hline & & acuminatus & $\begin{array}{l}\text { MZUPRRP-I- } \\
00347\end{array}$ & & \\
\hline & Serranidae & Hypoplectrus & UPR FL0324/ & $1,632,142$ & 943 \\
\hline & & nigricans & $\begin{array}{l}\text { MZUPRRP-I- } \\
00497\end{array}$ & & \\
\hline & Sparidae & Calamus penna & UPR FL0063/ & $3,576,529$ & 929 \\
\hline & & & $\begin{array}{l}\text { MZUPRRP-I- } \\
00281\end{array}$ & & \\
\hline SynPela & Bramidae & Brama orcini & USNM 403327 & $2,359,571$ & 1027 \\
\hline (96 Ma) & Centriscidae & $\begin{array}{l}\text { Macroramphosus } \\
\text { scolopax }\end{array}$ & USNM 405231 & $2,823,407$ & 1034 \\
\hline & Chiasmodontidae & Kali macrura & USNM T2229 & 643,335 & 973 \\
\hline & Gempylidae & $\begin{array}{l}\text { Lepidocybium } \\
\text { flavobrunneum }\end{array}$ & USNM 407069 & $2,559,203$ & 1065 \\
\hline & Mullidae & Upeneus tragula & USNM 403208 & $3,042,224$ & 918 \\
\hline & Scombridae & $\begin{array}{l}\text { Rastrelliger } \\
\text { brachysoma }\end{array}$ & USNM 409000 & $2,423,976$ & 1016 \\
\hline & Stromateidae & Peprilus snyderi & USNM 421333 & $1,581,129$ & 1044 \\
\hline & Syngnathidae & $\begin{array}{l}\text { Syngnathus } \\
\text { pelagicus }\end{array}$ & USNM 423115 & $1,244,405$ & 867 \\
\hline
\end{tabular}

$636{ }^{\mathrm{a}}$ United States National Museum (Smithsonian Institution), Washington, DC; ${ }^{\mathrm{b}}$ Commonwealth 637 Scientific and Industrial Research Organisation, Tasmania, Australia; ${ }^{\mathrm{C}}$ Zoological Museum at 638 University of Puerto Rico-Rio Piedras, San Juan, PR. Specimens without a MZUPRRP number 639 have no voucher due to their small size, only a field number beginning with FL; ${ }^{\mathrm{d}}$ Smithsonian 640 Tropical Research Institute, Panama.

641

642 Table 3. Legacy markers and their paralogs assembled from exon-capture data.

\begin{tabular}{lll}
\hline Locus ID & Gene Name & Paralogs Assembled \\
\hline E1541 & TBR1 & - \\
E1728 & KIAA1239 & - \\
E1730 & MYH6 & MYH7, MYH6-like, MYHb \\
E1732 & ENC1 & ENC2 \\
E1735 & PLAGL2 & (Failed to assemble) \\
E1736 & PTCHD1 & - \\
E1737 & RIPK4 & SNX18 \\
E1738 & SH3PX3 (SNX33) & - \\
E1739 & SIDKEY & GPR173 \\
E1740 & SREB2 (GPR85) & ZIC4 \\
E1741 & ZIC1 & - \\
E1746 & SVEP1 & - \\
E1747 & GPR61 & - \\
E1748 & IRBP & RNF213b-like, RNF213a-like \\
E1749 & RNF213 & EXORH \\
E1750 & RH &
\end{tabular}




$\begin{array}{lll}\text { E1751 } & \text { SLC10A3 } & - \\ \text { E1752 } & \text { UBEA3 } & - \\ \text { E1753 } & \text { UBEA3-like } & \text { UBEA3 }\end{array}$

\section{Figure Legends}

Figure 1: Position of Elopomorpha and Backbone 1 probe sets in the Maximum likelihood analysis of protein from 394 fish taxa, combining genomes, transcriptomes, and exon capture. Newly sequenced taxa are represented with black dots at the tips. This clade has a specific probe set with a different but overlapping set of exons designed in an earlier study, Arcila et al. (2017), but is not specifically targeted by Backbone 1.

Figure 2: Position of Backbone 2 and Ovalentaria probe sets in the Maximum likelihood analysis of 394 fish taxa, combining genomes, transcriptomes, and exon capture. Newly sequenced taxa are represented with black dots at the tips.

Figure 3: Position of Carangaria, Syngnatharia-Pelagiaria (Syn-Pela) and Eupercaria probe sets in the Maximum Likelihood analysis of 394 fish taxa, combining genomes, transcriptomes, and exon capture. Newly sequenced taxa are represented with black dots.

Figure 4: Major steps of bioinformatics pipeline and software used to transform data from Illumina reads to multiple sequence alignments. Scripts and pipeline tutorial are available on GitHub (https://github.com/lilychughes/FishLifeExonCapture).

Figure 5: A) Box-and-whisker plots showing the variation in the number of exons captured for each probe set. Eight newly sequenced taxa were used for each probe set. Percentages above each box refer to the average percentage of exons assembled by probe set. B) The average number of loci captured for each of the seven probe sets plotted against the age of the most recent common ancestor of that particular group, showing higher capture of loci for younger clades. C) Percent sequence identity and length across alignments of eight model genomes ( $L$. oculatus, A. japonica, D. rerio, G. morhua, O. latipes, O. niloticus, G. aculeatus, and T.

673 triangles). 
therion preprint doi: https://doi.org/10.1101/2020.02.18.949735; this version posted February 19, 2020. The copyright holder for this preprint

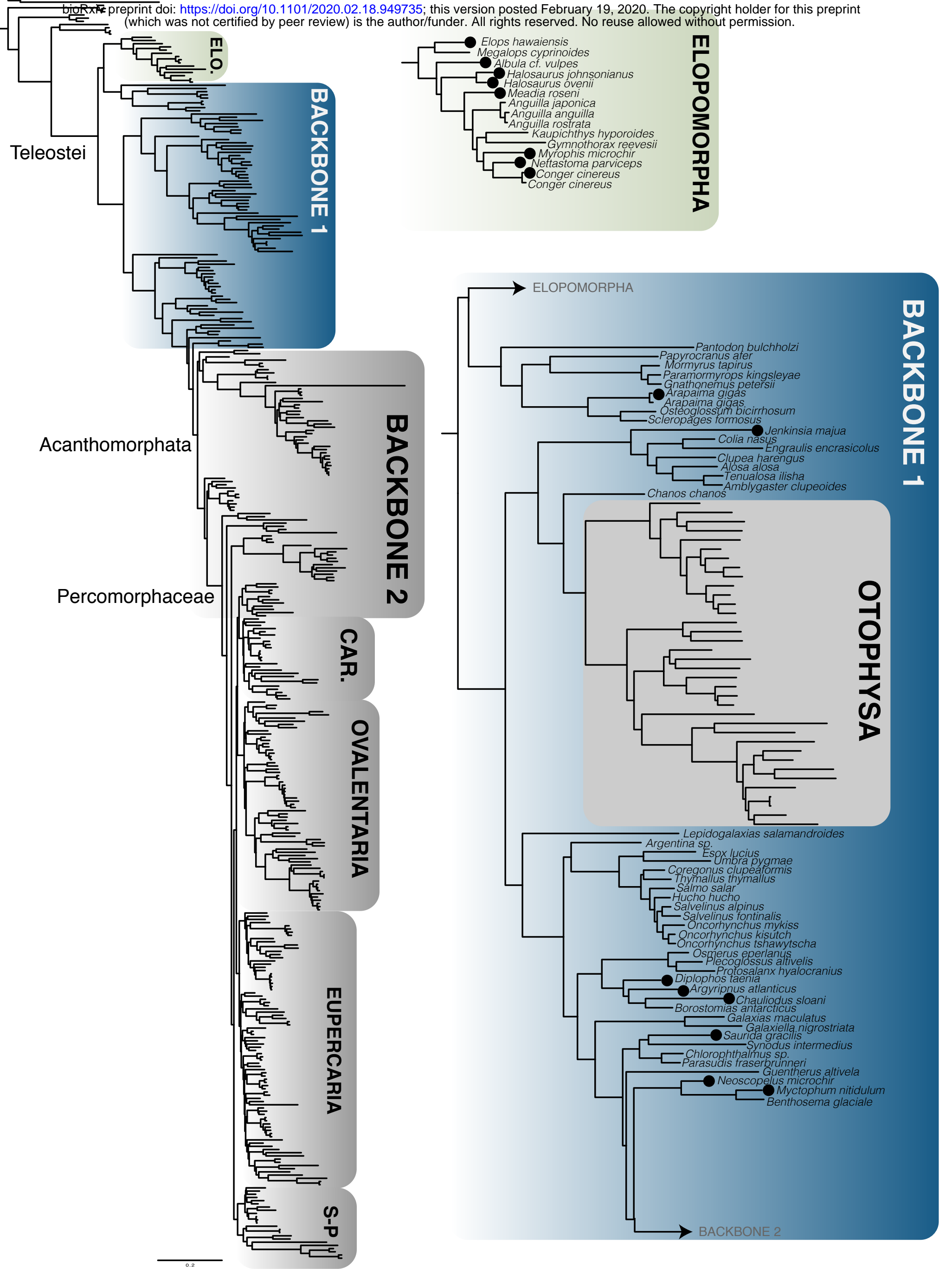




\section{Quality trim Reads}

Trimmomatic

Map reads to reference sequences

\section{BWA, Samtools}

Assemble reads by locus \& extract longest contig

Velvet, getLongest.py

Extend initial contigs into longer contigs

aTRAM (BLAST, Trinity)

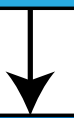

Remove redundant contigs \& find reading frame

CD-Hit, Exonerate, FilterExons.py

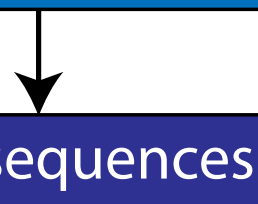


